\title{
La productividad en las economías desarrolladas: el desigual impacto de la crisis*
}

\author{
Matilde Mas Ivars \\ Universitat de València \\ Instituto Valenciano de Investigaciones Económicas (Ivie)
}

\section{Resumen}

El trabajo aborda el problema de la productividad en España desde una perspectiva internacional comparada. Analiza el comportamiento de 25 países de la UE, Estados Unidos y Japón durante la fase expansiva 1995-2007 y los cuatro posteriores de crisis. Argumenta que el lento avance de la productividad en la expansión no es atribuible exclusivamente al sector de la construcción pues fue general a prácticamente todos los sectores. En su origen se encuentra el gran esfuerzo realizado en la acumulación de capital ligado a actividades inmobiliarias y una pérdida generalizada de eficiencia.

Palabras clave: productividad del trabajo, productividad total de los factores (PTF), expansión, crisis.

JEL: $O 4$.

\begin{abstract}
The paper addresses the problem posed by the productivity in Spain from an international perspective. It analyzes the behavior followed by 25 EU countries, United States and Japan during the expansion years 1995-2007 and the following four years of crisis. It argues that the sluggish productivity growth during the expansion is not to be blamed only on the construction industry since it was a general phenomenon shared by almost all economic sectors. Its origin must be found in the great effort undertaken in capital accumulation related with real estate together with a generalized loss of efficiency.
\end{abstract}

Keywords: labour productivity, total factor productivity (TFP), expansion, crisis.

JEL: 04 .

\section{Introducción}

Los perfiles seguidos por la productividad del trabajo en España no han recibido la atención que merecen, especialmente si se tiene en cuenta su importancia en el buen funcionamiento de las economías. El crecimiento de la productividad importa al menos por los siguientes motivos. En primer lugar, porque es el principal motor del avance de la renta por habitante, variable que se utiliza habitualmente como indicador de los niveles y ganancias de bienestar experimentadas por las sociedades. En épocas de expansión, con la economía próxima al pleno empleo, las ganancias de

* El artículo se inscribe en el proyecto de investigación de la DGCYT Productividad y competitividad en la sociedad del conocimiento (ECO2011-23248), cuya ayuda financiera se agradece. 
productividad - junto con el crecimiento de la población activa - se convierten en los motores que impulsan las ganancias en renta per cápita. Sin embargo, en periodos de crisis - como la que estamos atravesando desde hace ya demasiados años - el crecimiento del empleo se convierte en el tercer factor imprescindible para que la renta crezca, para que mejore el bienestar de la población. En definitiva, para que las economías avancen por sendas de progreso resulta imprescindible que se combinen dos hechos: ganancias de productividad junto con reducciones de la población dependiente, bien por la vía de mayor incorporación de la población al mercado de trabajo - el aumento de la población activa - y/o el aumento de la población ocupada.

En este artículo nos centraremos casi exclusivamente en la variable productividad, aunque sin olvidar el comportamiento seguido por el empleo. No nos referiremos, por el contrario, a la evolución de la población activa sin que ello indique que se considere una variable menos relevante. De hecho, uno de los hechos más fundamentales que han tenido lugar en la economía española en los últimos treinta años ha sido la decidida incorporación de la mujer al mercado de trabajo, lo que debe valorarse como un hecho crucial en la aproximación hacia sistemas productivos y sociales avanzados. El segundo hecho ha sido la fortaleza de los movimientos migratorios comenzada con singular ímpetu a finales de la década de los noventa del siglo pasado, y en fase de desaceleración o de franco declive en la actualidad.

La segunda razón por la que es importante que la productividad aumente es porque permite que también lo hagan los salarios reales sin generar tensiones en el mercado de trabajo con consecuencias negativas sobre el desempleo. En su versión más elemental, cuando los salarios reales crecen a tasas más elevadas que la productividad los empresarios optimizadores - que tienen como objetivo la maximización del beneficio - estarán dispuestos a contratar menos trabajadores con efectos negativos sobre el empleo. Por supuesto, existen otros factores que afectan al funcionamiento del mercado de trabajo - incluyendo su regulación, las instituciones en las que descansa o el poder negociador de trabajadores y empresarios, entre otros- pero en cualquier caso se mantiene como norma para un buen funcionamiento de las economías, que el crecimiento de los salarios acompase a los avances de productividad.

En tercer lugar, en economías abiertas, el crecimiento de los salarios por encima de la productividad empujan al alza los costes laborales unitarios perjudicando su competitividad precio, desalentando las exportaciones y haciendo más atractivas las importaciones, con efectos negativos sobre la demanda externa, el saldo de la balanza comercial, y aumentando la necesidad de financiación externa con los efectos negativos que nos resultan bien conocidos.

El trabajo se centra en el análisis del comportamiento seguido por la productividad en las economías más avanzadas, comenzando con la Unión Europea de los veinticinco $(\mathrm{UE}-25)^{1}$. Por su interés, distinguiremos en el análisis entre los quince países que integraron inicialmente la Unión (UE-15) y los Nuevos Estados Miembros procedentes en su mayoría de la órbita de la antigua Unión Soviética (Letonia,

\footnotetext{
${ }^{1}$ Previa a la entrada de Bulgaria y Rumanía.
} 
Estonia, Lituania, Polonia, República Checa, Eslovaquia, Eslovenia y Hungría) y dos pequeños países, Malta y Chipre, a los que nos referiremos como UE-10.

La evolución de estas economías se compara con dos grandes países - o regiones si se prefiere dada su extensión no solo física sino también económica - Estados Unidos y Japón. El primero es el país que todavía lidera la economía mundial, aunque su prominente posición se encuentre amenazada en la actualidad por las economías emergentes agrupadas bajo la denominación de $\mathrm{BRICS}^{2}$, y en especial por China. El segundo país de referencia será Japón, país que mostró un extraordinario dinamismo después de la segunda gran guerra, aproximándose vertiginosamente a Estados Unidos hasta alcanzar la segunda posición en el ranking mundial. Sin embargo, desde finales del siglo xx se encuentra inmerso en una profunda crisis, en muchos aspectos similar a la que está atravesando la economía española en la actualidad. El estallido de la burbuja inmobiliaria y las dificultades de su sistema financiero son los hechos más llamativos, aunque no los únicos, que aproximan nuestras actuales dificultades a las de Japón. Por esta razón resulta también interesante comparar a España no solo con los líderes (Estados Unidos), o sus socios comerciales (UE-25), sino también con el país que después de un crecimiento fulgurante entró en una larga etapa de recesión tras los excesos cometidos en los años de fuerte crecimiento.

El análisis que se presenta a continuación cubre el periodo más reciente: los últimos dieciséis años, que se inician en 1995 con el despegue de una fuerte etapa expansiva tras la breve, pero severa, recesión de comienzos de los noventa, y termina con la abrupta recesión que sumió a la economía mundial en la que todavía estamos inmersos. Por esta razón, el conjunto del periodo 1995-2011 lo dividiremos en dos etapas claramente distintas: los años de vino y rosas del periodo más largo de crecimiento en la historia reciente de la economía española, 1995-2007, y los años posteriores, 2007-2011, en los que despertamos del sueño y en los que todavía continuamos inmersos.

La información estadística que se utiliza a lo largo del capítulo procede de la base de datos EU KLEMS (2011) resultado de un proyecto de investigación financiado por el VII Programa Marco de la Unión Europea, y en el que han participado dieciocho instituciones. El Instituto Valenciano de Investigaciones Económicas (Ivie) ha sido el responsable para España del Proyecto. Una primera presentación de sus resultados con especial referencia a España puede encontrarse en Mas y Robledo (2010). Una visión global presentando el proyecto, la metodología seguida, y sus principales conclusiones se encuentra en Timmer, Inklaar, O’Mahony y Van Ark (2010). Por su parte, Mas y Stehrer (2012) presenta una serie de panorámicas de las trayectorias seguidas por los países analizados en el proyecto, así como una colección de artículos explotando los resultados más relevantes del mismo ${ }^{3}$.

La base de datos EU KLEMS ofrece un elevado grado de desagregación sectorial lo que la convierte en especialmente atractiva. Sin embargo, tiene el inconveniente

\footnotetext{
${ }^{2}$ Se emplean estas siglas para referirse conjuntamente a Brasil, Rusia, India, China y Sudáfrica.

${ }^{3}$ CUADRADO y MAROTO (2012) presentan un cuidadoso análisis centrado en España.
} 
de que el último dato disponible corresponde a 2007, lo que permite analizar con detalle la etapa de expansión pero no los años posteriores de crisis ${ }^{4}$. Sin embargo, para las variables agregadas sí es posible ofrecer una visión actualizada haciendo uso de los datos ofrecidos por The Conference Board (TCB 2012), anteriormente conocida como The Total Economy Database del Groningen Growth and Development Center en la Universidad de Groningen (Países Bajos).

El artículo se estructura de la forma siguiente. El apartado 1 ofrece una panorámica de las principales variables agregadas, Valor Añadido Bruto (VAB); empleo (medido en horas trabajadas); productividad del trabajo; salarios; y coste laboral unitario. El apartado 2 entra en el detalle sectorial mientras que el apartado 3 analiza las fuentes del crecimiento y el papel jugado por las nuevas tecnologías de la información y la comunicación. Por último, el apartado 4 se destina a las reflexiones finales.

\section{Las variables agregadas}

Un rápido repaso de las variables macroeconómicas nos permite comprobar con facilidad dos hechos: el fuerte dinamismo de los años de expansión, y la ruptura que ha supuesto la grave crisis en la que nos encontramos. El VAB de la economía española creció en el periodo 1995-2011 a una tasa no despreciable, el 2,5 por 100 anual (Gráfico 1). Esta tasa de crecimiento solo fue superada por el conjunto de nuevos estados miembros (UE-10) que han sabido aprovechar las ventajas de una posición de partida relativamente más atrasada, como también ocurrió en España tras la adhesión a la Unión Europea. Los Nuevos Estados Miembros han crecido más rápido gracias, fundamentalmente, a los bajos salarios que presentan en relación con los países más desarrollados de la UE - lo que ha favorecido la inversión directa extranjera, especialmente en los sectores manufactureros - y el aprovechamiento de su distancia hacia la frontera tecnológica, lo que le permite copiar los nuevos avances sin verse forzados a innovar, que es un proceso más caro y más incierto. El líder mundial, Estados Unidos, también avanzó a buen ritmo, superando ampliamente a los países que integran el núcleo central de la Unión Europea (UE-15). Por el contrario, el crecimiento del VAB en Japón fue muy lento, la mitad de la UE-15, o la tercera parte de España y Estados Unidos. Por lo tanto, si revisamos el conjunto del periodo 1995-2011 que incluye doce años de expansión y cuatro de recesión, comprobamos que España - aún teniendo en cuenta estos últimos años - ocupa una posición muy destacada, junto con la UE-10, y Estados Unidos; la UE-15 presentó un crecimiento más modesto; y Japón una trayectoria francamente mediocre.

${ }^{4}$ En http://www.euklems.net ya está disponible la nueva base de datos EU KLEMS en NACE Rev. 2. con resultados actualizados a 2009. Hasta el momento solo ofrece información para seis países de la Unión Europea: España, Francia, Austria, Reino Unido, Alemania e Italia. 


\section{GRÁFICO 1 \\ TASA DE VARIACIÓN ANUAL DEL VALOR AÑADIDO \\ BRUTO, 1995-2011 \\ (En \%)}

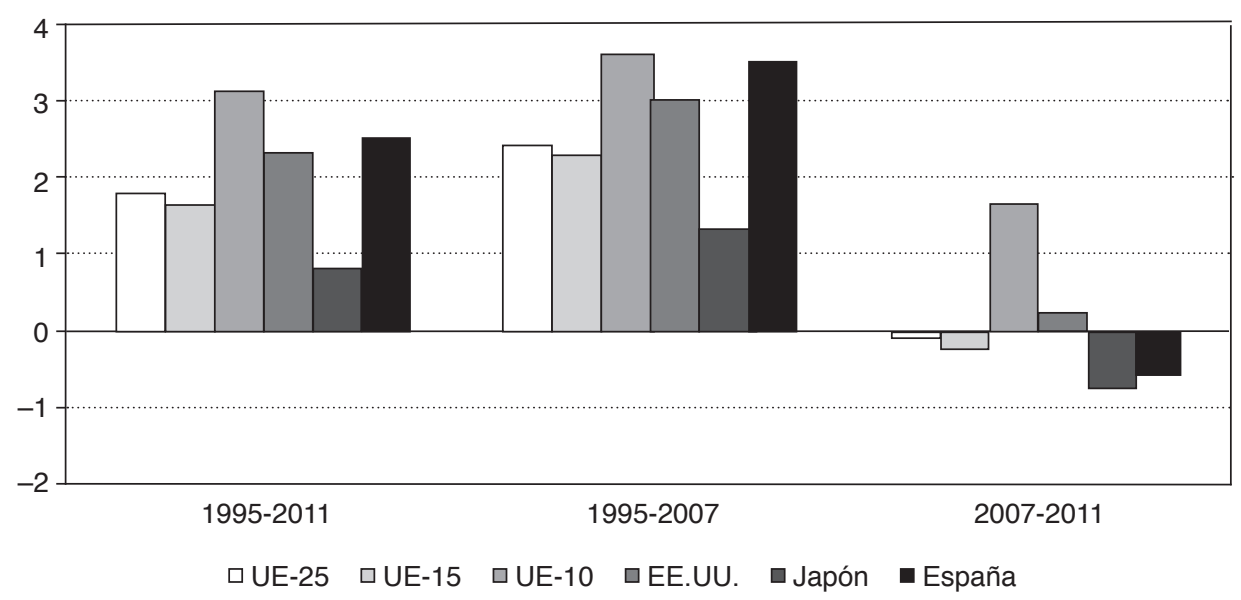

FUENTE: EU KLEMS (2011) y TCB (2012).

El ordenamiento anterior es el resultado de lo ocurrido en los años de expansión, 1995-2007, cuando el crecimiento del VAB de España se aproximó al de la UE-10, y superó en medio punto al de Estados Unidos; en más de un punto porcentual a la UE15; y más de dos puntos al crecimiento de Japón. Incluso en estos años de importante crecimiento Japón se desmarcó de las economías más desarrolladas, avanzando muy lentamente. Las consecuencias de la crisis iniciada en el segundo semestre de 2007 fueron devastadoras. Solo los Nuevos Estados Miembros consiguieron mantener el crecimiento positivo del VAB a una tasa superior al 1 por 100 y Estados Unidos al 0,2 por 100 entre 2007-2011, mientras en la UE-15, España, y sobre todo Japón, el crecimiento medio en estos cuatro años fue negativo.

Los perfiles seguidos por el empleo (medido en horas trabajadas) fueron todavía más desoladores (Gráfico 2). En el conjunto del periodo 1995-2011, todos los agregados que estamos considerando consiguieron crear empleo, excepto Japón, que lo destruyó a buen ritmo en línea con la larga crisis por la que está atravesando, mientras los nuevos estados miembros lo mantuvieron prácticamente estable. España ha sido, con gran diferencia, el país que más empleo ha creado en estos dieciséis años. Este resultado ha sido posible gracias a la intensísima creación de empleo de los años de expansión, 1995-2007, en que prácticamente triplicó las tasas de Estados Unidos y UE-15, mientras Japón fue el único que experimentó crecimientos negativos. La situación cambió drásticamente en los cuatro años siguientes. Todos los agregados geográficos presentaron crecimientos negativos, pero de un orden de magnitud muy distinto. España, Japón y Estados Unidos fueron los que más empleo perdieron, y los nuevos estados miembros los que menos. 


\section{GRÁFICO 2}

TASA DE VARIACIÓN ANUAL DE LAS HORAS TRABAJADAS, 1995-2011

(En \%)

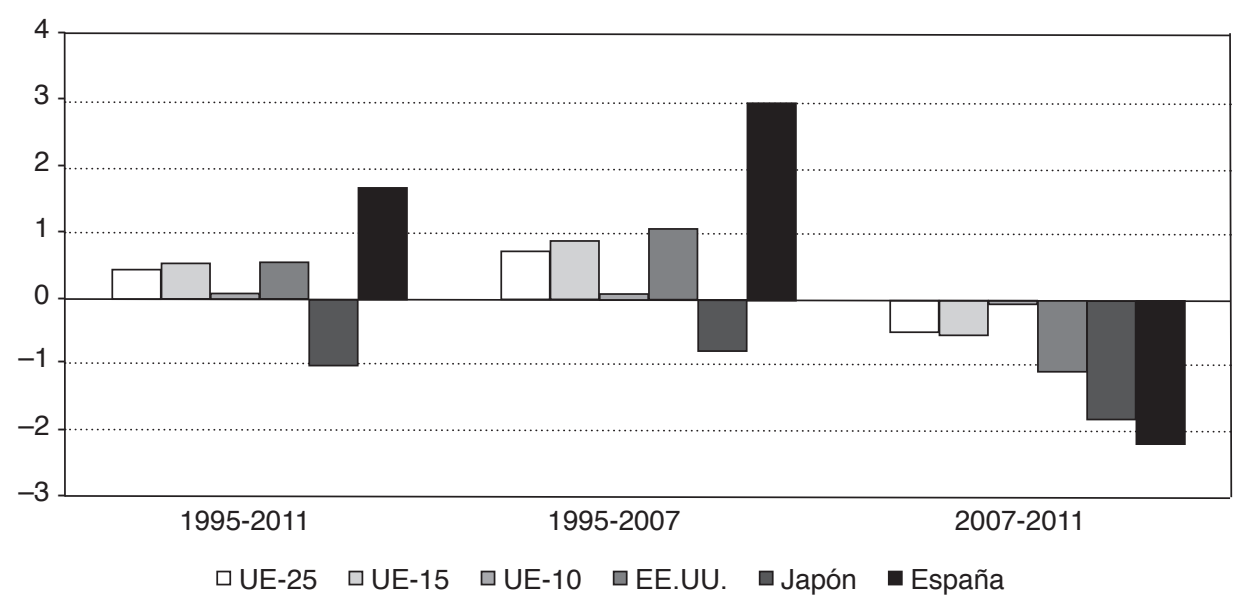

FUENTE: EU KLEMS (2011) y TCB (2012).

Las trayectorias del VAB y el empleo tuvieron las consecuencias sobre la productividad del trabajo que ilustra el Gráfico 3. Las mayores ganancias de productividad en el periodo completo, 1995-2011, las alcanzaron los países de la UE-10, seguidos de Japón y Estados Unidos. Sin embargo, los orígenes de las mejoras en esta variable fueron muy distintos. En la UE-10 se fundamentó en los rápidos avances del producto con prácticamente nulo crecimiento del empleo, mientras en Japón, fue el resultado de modestos crecimientos del VAB unidos a importante destrucción del factor trabajo. Por el contrario, Estados Unidos presentó un comportamiento virtuoso ya que consiguió tasas elevadas de crecimiento de la productividad al tiempo que creaba empleo neto. 


\section{GRÁFICO 3}

\section{TASA DE VARIACIÓN ANUAL DE LA PRODUCTIVIDAD POR HORA TRABAJADA, 1995-2011 \\ (En \%)}

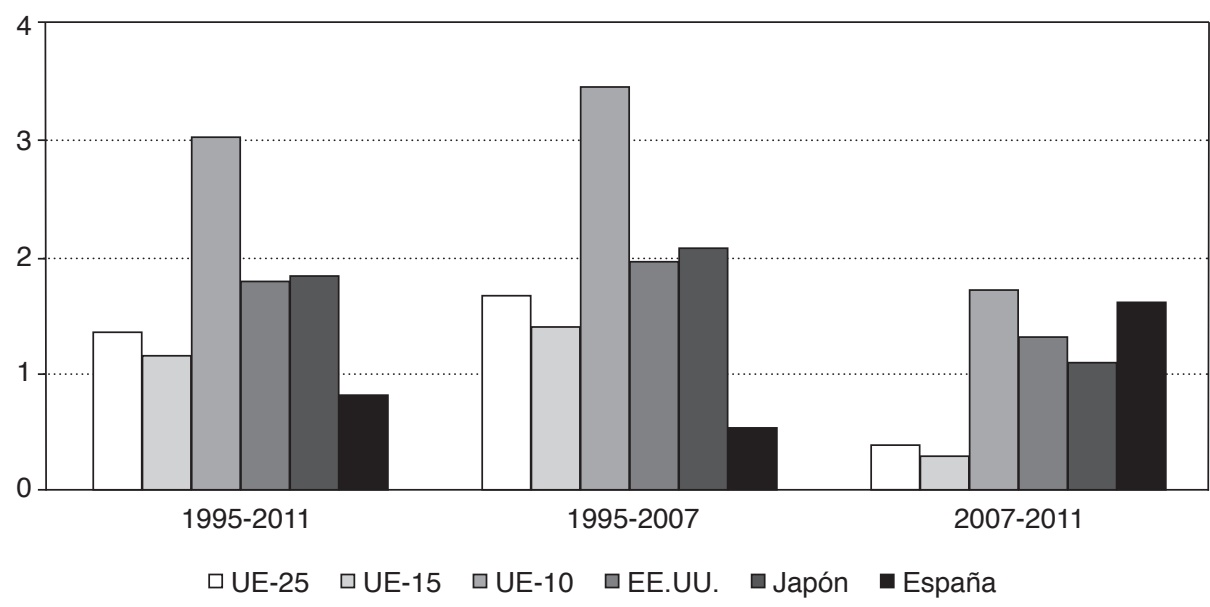

FUENTE: EU KLEMS (2011) y TCB (2012).

El comportamiento de Estados Unidos en estos años es el auténtico referente para todas las economías, especialmente la española, para la que el objetivo debe ser mejorar la productividad al tiempo que se crea empleo. Estos deben ser nuestros dos objetivos ineludibles en el discurso sobre el «cambio en el modelo productivo». Sin embargo, en España las trayectorias han sido justo las opuestas. Durante los años de expansión el dinamismo del VAB y el empleo fue muy notable pero con muy pobres avances de la productividad: la cuarta parte de Estados Unidos, un tercio de la UE15 , o el 15 por 100 de la UE-10. Con la llegada de la crisis, la intensísima destrucción de empleo impulsó al alza la productividad del trabajo en lo que se ha interpretado como un resultado positivo dentro del desolador panorama al que nos enfrentamos. Sin embargo, como tendremos ocasión de comprobar más adelante, la lectura positiva de este hecho ofrece más sombras que luces.

Por su parte, Japón es un ejemplo en el que no debemos mirarnos, ya que el crecimiento de la productividad que ha conseguido en estos años ha sido el resultado de muy lentos avances del producto - negativo en los años de crisis - unido a un proceso continuo de destrucción de empleo. En los últimos dieciséis años - desde que inició su particular crisis de la que no consigue recuperarse - se ha convertido en una economía estancada incapaz de mantener ocupada a su fuerza de trabajo.

Las informaciones anteriores han ofrecido los resultados agregados para la UE-25, UE-15 y UE-10. Sin embargo, la Unión Europea está lejos de ser un agregado uniforme como los hechos recientes se están encargando de evidenciar. Pese a su intenso dinamismo, España no fue el país que presentó la tasa más elevada de crecimiento del $\mathrm{VAB}$ en los años de expansión, ya que los tres países bálticos, Irlanda, Luxemburgo 
y Finlandia consiguieron crecer a tasas más elevadas que nosotros (Gráfico 4). Por su parte, dos países de la UE-15 que están recibiendo en la actualidad gran atención, aunque por razones justamente opuestas, Alemania e Italia, fueron los que menos crecieron en estos años. En los cuatro años transcurridos desde que se inició la crisis todos los países de la UE experimentaron desaceleraciones en la tasa de crecimiento del VAB, y muchos presentaron crecimientos negativos, aunque no todos.

\section{GRÁFICO 4}

TASA DE VARIACIÓN DEL VAB. UE-15 Y UE-10, 1995-2011

(En \%)

a) UE-15

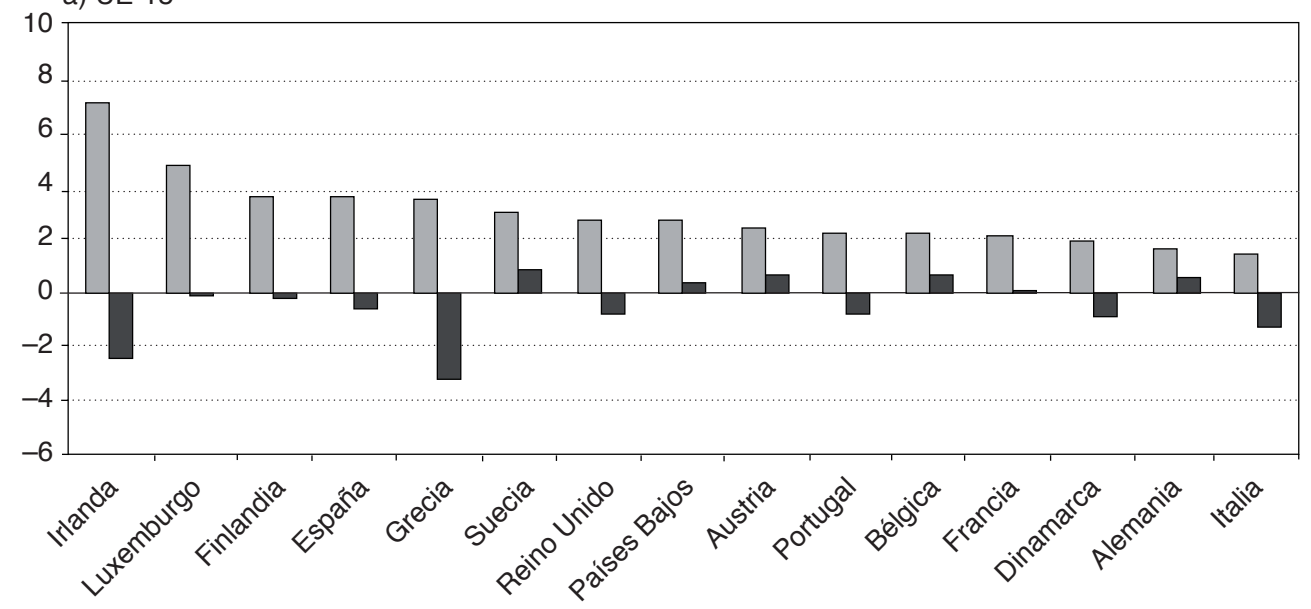

b) UE-10

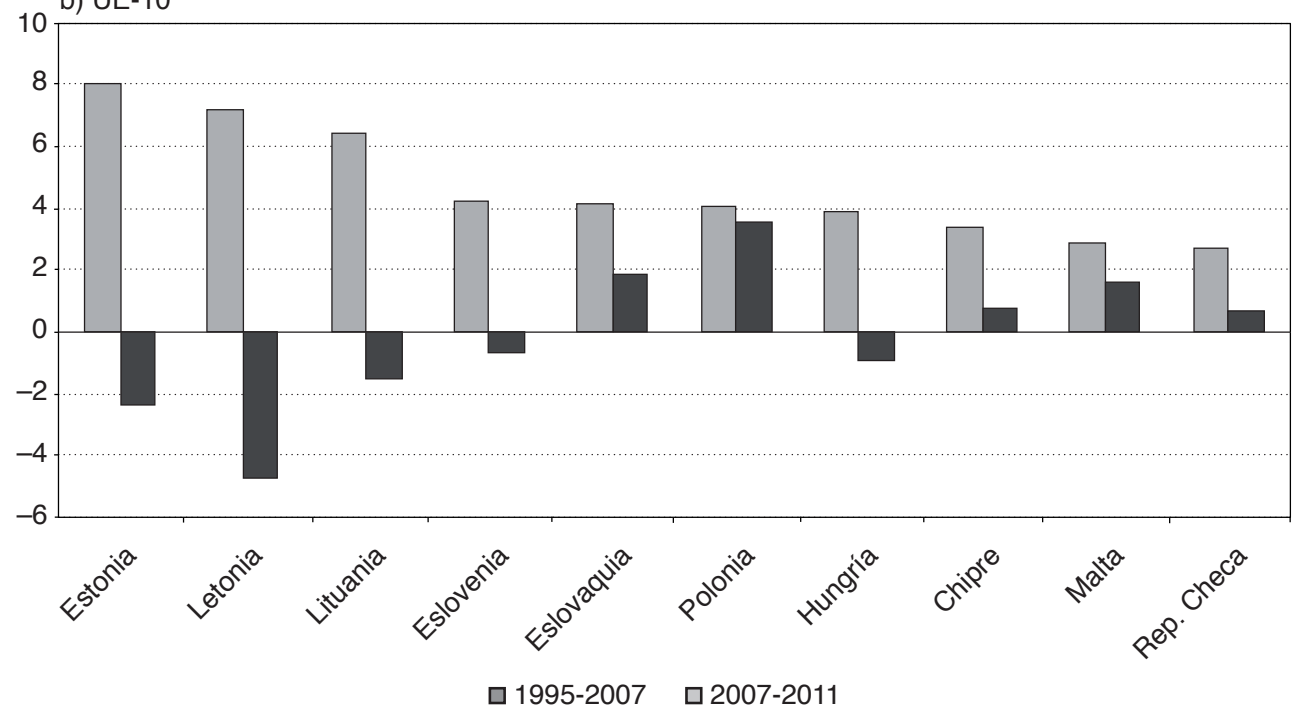

FUENTE: EU KLEMS (2011) y TCB (2012). 
Dentro de los países de la UE-15, las mayores caídas las han presentado dos países intervenidos, Grecia e Irlanda, seguidos por otros dos que se encuentran en la actualidad en el punto de mira, Italia y España. Portugal, el tercer país intervenido ha presentado tasas de crecimiento negativas pero menores en valor absoluto a las de Italia y Dinamarca. En el otro extremo, seis países de la UE-15 se han mantenido en valores positivos: Suecia, Bélgica, Francia (con práctico estancamiento), Alemania, Países Bajos y Austria. Son precisamente los tres últimos, con Alemania ejerciendo el liderazgo, los que se manifiestan más reticentes a ayudar a los países con problemas, y también los defensores a ultranza de las políticas de austeridad.

En el grupo de países de la UE-10 destacan dos hechos: la intensidad de la caída en los tres países bálticos, especialmente en Letonia, y el buen comportamiento de Polonia que se ha mantenido prácticamente inmune al vendaval de la crisis. No es sorprendente que este país se alinee con el grupo menos favorable al rescate de las economías con problemas.

Tampoco fue España el país que presentó las tasas de crecimiento más elevadas de creación de empleo - aunque sí el que más empleo creó en términos absolutos en los años de expansión (Gráfico 5). Luxemburgo e Irlanda se sitúan por delante, y dos países nórdicos, Finlandia y Dinamarca, justo detrás. El hecho seguramente más notable es que durante estos años la gran mayoría de países de la UE crearon empleo, con tan solo tres excepciones: Alemania, dentro del grupo de la UE-15, y la República Checa y Eslovaquia, en la UE-10.

Con la llegada de la crisis la destrucción de empleo se extendió por el conjunto de la Unión, pero su intensidad fue muy desigual, y tampoco fue general para todos los países. En la UE-15 las mayores caídas las experimentaron los tres países intervenidos - Irlanda, Grecia y Portugal, especialmente el primero - junto con otros dos que están sufriendo con especial gravedad las consecuencias de la crisis, España e Italia, y un país nórdico, Dinamarca, que ha seguido una trayectoria mediocre en los últimos años (Hagén, 2011). En el otro extremo, solo tres países de la UE-15 no han destruido empleo en estos años, Bélgica, Suecia y Alemania que, como hemos visto, fue el único país que sí redujo el contingente laboral en los años de expansión.

Desde la perspectiva de la productividad del trabajo las imágenes son bien distintas (Gráfico 6). Entre los años 1995 y 2007 prácticamente todos los países de la UE-10, con las tres repúblicas bálticas a la cabeza, experimentaron crecimientos de esta variable superiores a cualquiera de la UE-15. En el otro extremo, España e Italia fueron los que presentaron los avances más lentos de productividad. Con la llegada de la crisis todos los países experimentaron desaceleraciones importantes con una única excepción, España, que fue el único en el que la productividad creció más en la recesión que en la expansión. De hecho, creció tres veces más por las razones que se analizarán más adelante.

El crecimiento de los salarios es una variable clave en el funcionamiento de las economías. Desde la perspectiva agregada su evolución tiene consecuencias sobre al menos tres variables macroeconómicas: desempleo; inflación; y costes laborales unitarios. En el conjunto del periodo 1995-2011 los salarios crecieron en España 


\section{GRÁFICO 5}

TASA DE VARIACIÓN DE LAS HORAS TRABAJADAS, UE-15 Y UE-10, 1995-2011

(En \%)

a) UE-15

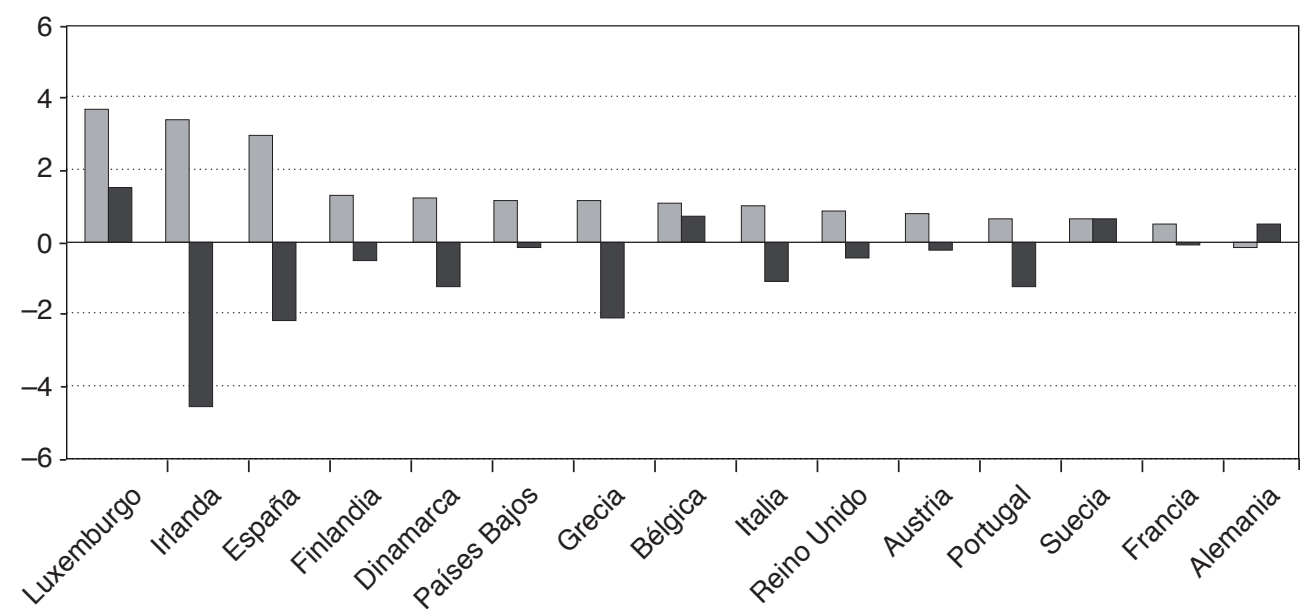

b) UE-10

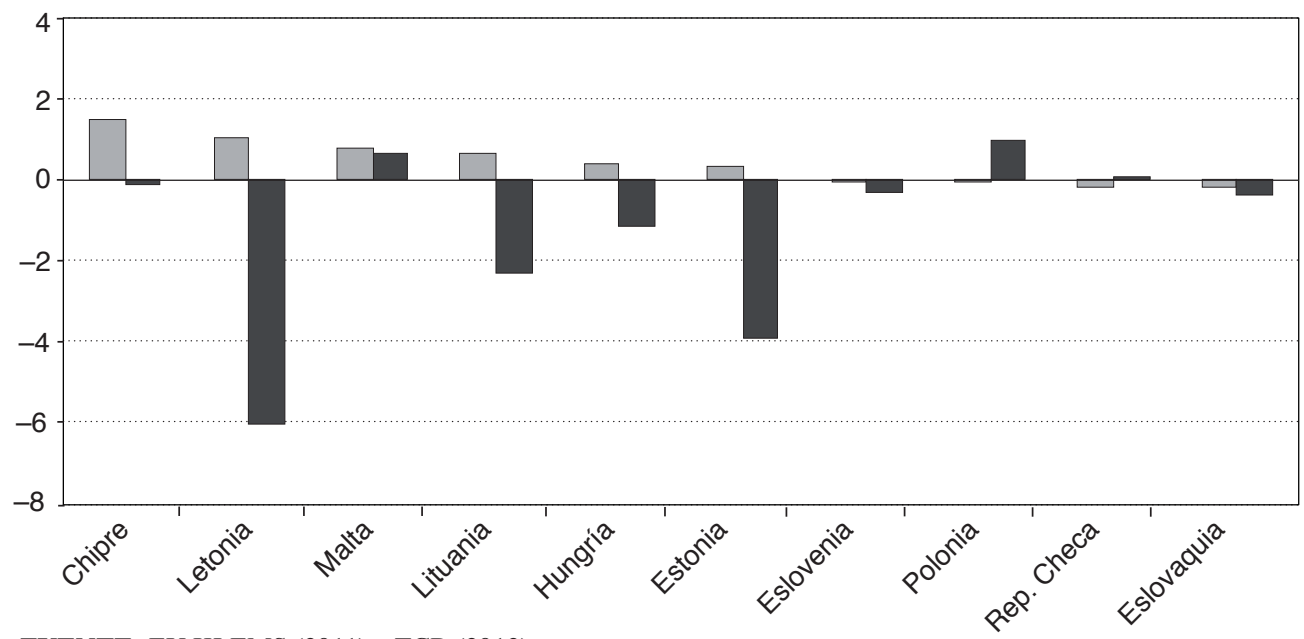

FUENTE: EU KLEMS (2011) y TCB (2012).

$\square$ 1995-2007 2007-2011 


\section{GRÁFICO 6}

TASA DE VARIACIÓN DE LA PRODUCTIVIDAD POR HORA TRABAJADA, UE-15 Y UE-10, 1995-2011

(En \%)

a) UE-15

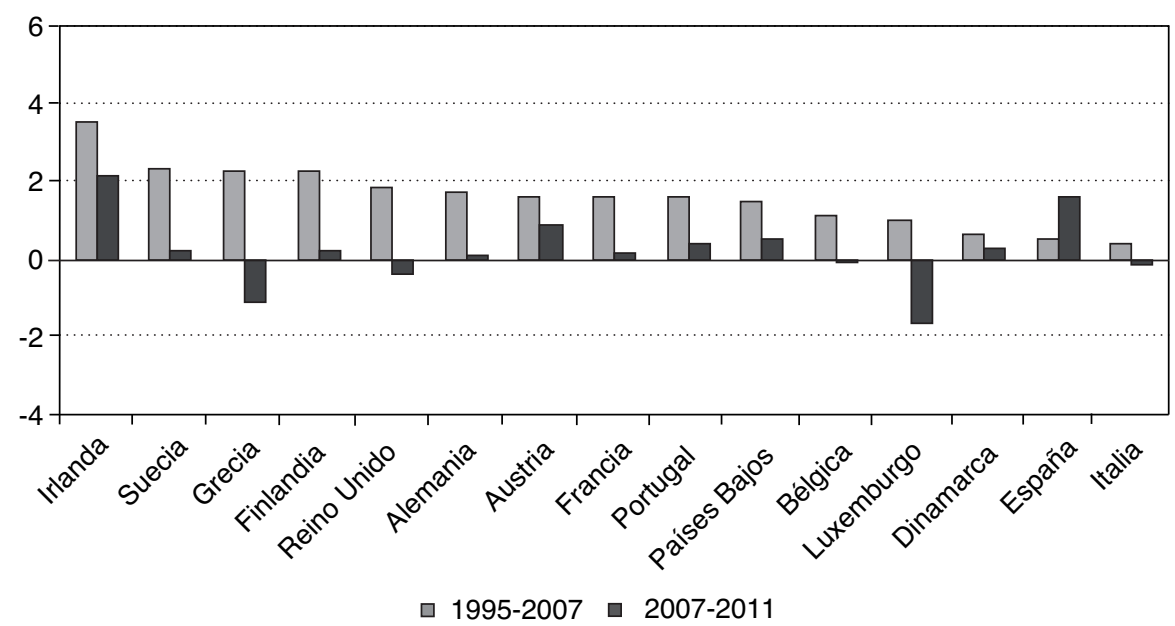

b) UE-10

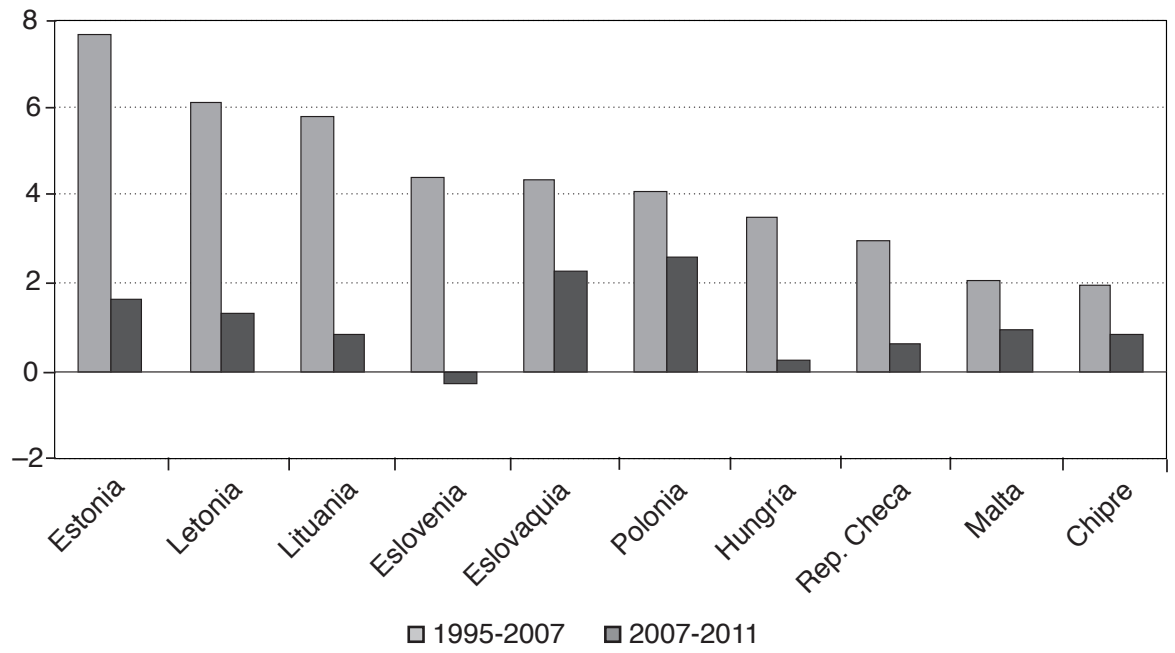

FUENTE: EU KLEMS (2011) y TCB (2010 y 2014).

solo algo menos que en Estados Unidos, y casi el doble que en la Eurozona-125 (Gráfico 7). Por el contrario, en Japón su avance fue muy moderado, aproximadamente la cuarta parte que en España, en consonancia con la fase recesiva por la que transita.

${ }^{5}$ El referente para esta variable es la Eurozona en lugar del conjunto de la Unión Europea por razones de disponibilidad estadística. 


\section{GRÁFICO 7}

TASA DE VARIACIÓN DE LOS SALARIOS, 1995-2011

(En \%)

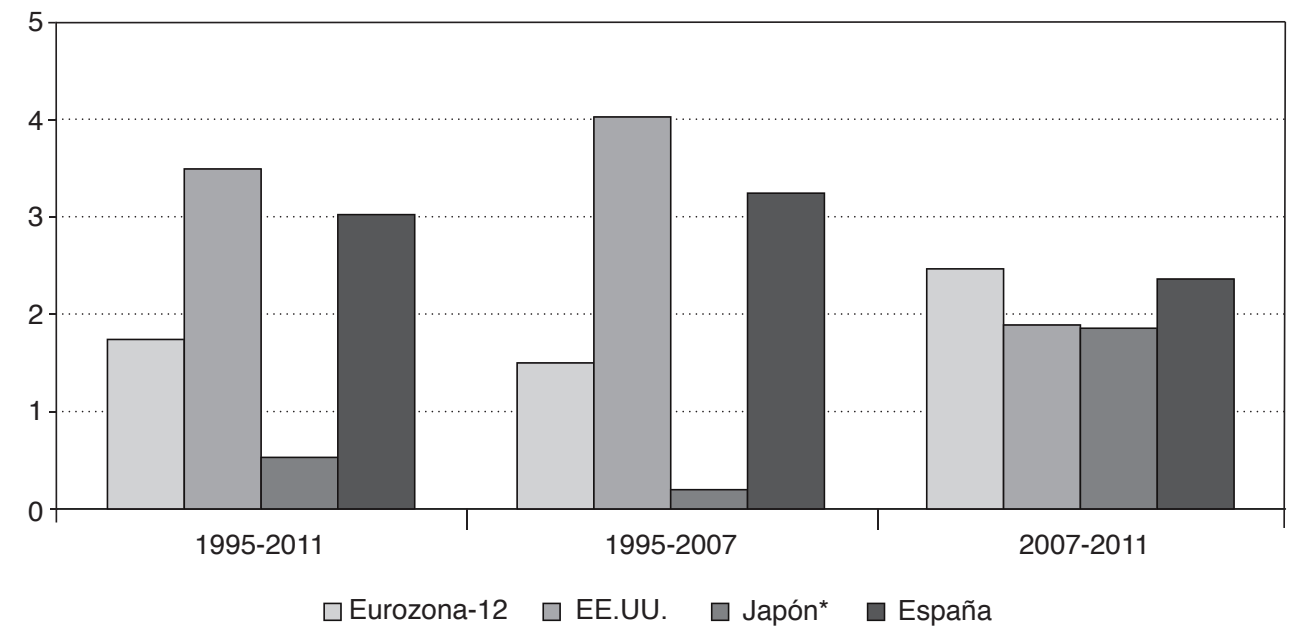

NOTA: * 1995-2010 y 2007-2010.

FUENTE: Banco Central Europeo (BCE 2012), EU KLEMS (2011), Eurostat (2012) y TCB (2012).

Los años de expansión conocieron un crecimiento muy notable de los salarios en Estados Unidos y España, pero no así en la Eurozona-12 - donde crecieron menos de la mitad que en España - y mucho menos en Japón, donde el crecimiento fue prácticamente nulo. Los años de crisis no consiguieron frenar el avance de los salarios, no al menos con la intensidad que la situación de elevado desempleo exigía. En España, donde el desempleo crecía desbocado, los salarios continuaron creciendo a una tasa anual del 2,4 por 100 en el periodo 2007-2011.

El crecimiento de los costes laborales suele presentar bastante inercia, especialmente en países como España donde estaba - al menos hasta la reforma del mercado de trabajo en febrero de 2012 - muy influida por los convenios pactados a nivel sectorial que incluían la denominada clausula de ultraactividad, es decir, la prórroga automática del convenio cuando no había acuerdo entre trabajadores y empresarios. Con la profundización de la crisis los salarios comenzaron a desacelerarse, y entre los años 2010 y 2011 consiguieron remitir de forma notable, en línea con la situación de elevado desempleo que padecemos (Pérez et al., 2012).

La competitividad de la economía depende, entre otros factores, de los costes laborales y de la vinculación de estos con la productividad. Crecimientos de los salarios superiores a la productividad elevan los costes laborales unitarios, al ser su variación igual a la diferencia entre el crecimiento de las dos primeras variables. Cuando esto ocurre se producen presiones sobre los márgenes y los precios. El crecimiento de los precios, la inflación, reduce el poder adquisitivo de todas las remune- 
raciones pactadas en términos nominales (salarios, pensiones, seguros de desempleo, o remuneración del ahorro pactado a un tipo fijo). En el caso en que los trabajadores tuvieran capacidad de repercutir el crecimiento de los precios sobre los salarios - como ha ocurrido en la economía española - se produce un aumento de los salarios reales con consecuencias adversas sobre el empleo. Este fenómeno es especialmente perjudicial para los trabajadores desempleados y para los que desempeñan trabajos temporales, un colectivo muy concentrado en jóvenes y mujeres. Además, la elevación de los precios y los costes laborales unitarios perjudican la competitividad exterior, al encarecer relativamente los productos de exportación y abaratar los de importación.

El crecimiento de los costes laborales unitarios en España fue superior al de Estados Unidos y la Eurozona-12 en el conjunto del periodo 1995-2011 como consecuencia del fuerte incremento de los salarios y el muy lento avance de la productividad en los años de expansión (Gráfico 8). Por el contrario, en los cuatro años de crisis, y pese a que los salarios continuaron creciendo, la productividad creció a tasas elevadas - como consecuencia de la intensa destrucción de empleo- conteniendo de esta forma el avance de los costes laborales unitarios y mejorando la competitividad precio de nuestra economía. La mejora de nuestro saldo exterior que ha propiciado la contención de los costes laborales unitarios es seguramente el único signo positivo en el desolado panorama por el que transitamos.

\section{GRÁFICO 8}

TASA DE VARIACIÓN DEL COSTE LABORAL UNITARIO, 1995-2011

(En \%)

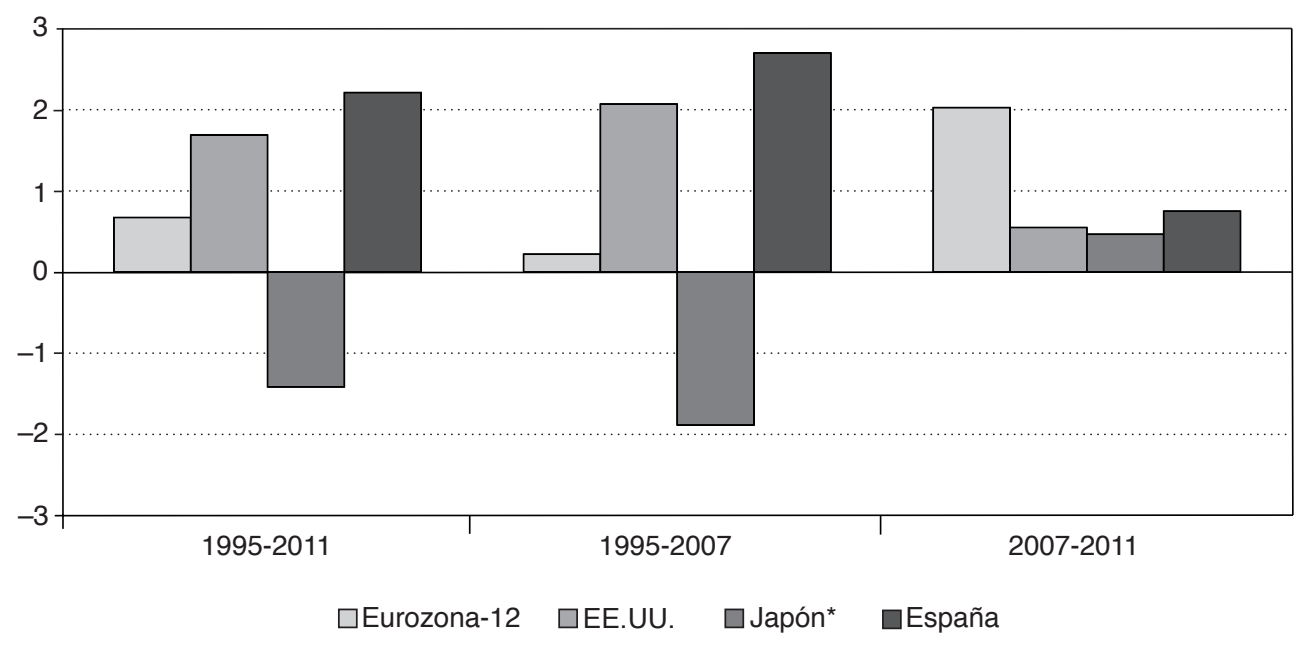




\section{La importancia de la desagregación sectorial}

Los comportamientos agregados suelen esconder muy distintas realidades desde la perspectiva sectorial, y también empresarial ${ }^{6}$. Se ha señalado en el apartado anterior que el muy lento avance de la productividad del trabajo en la economía española fue una de sus mayores debilidades en los años de expansión. De hecho, España e Italia fueron los dos países de la Unión Europea en los que esta variable presentó el comportamiento más mediocre entre 1995 y 2007, y son también estos dos países los que se enfrentan en la actualidad a importantes problemas macroeconómicos. Con la crisis y la fuerte destrucción de empleo que llevó, y lleva, aparejada, la productividad del trabajo se recuperó de forma importante en España, al contrario que en los restantes países donde se desaceleraba o incluso retrocedía.

Cuando se analiza desde una perspectiva sectorial se observan dos hechos de interés (Gráfico 9). El primero, que el lento avance de la productividad en los años de expansión fue un fenómeno que afectó no sólo al sector de la construcción - que experimentó una tasa de crecimiento negativa del 1,5 por 100 anual - sino que se extendió a los dos grandes sectores económicos, servicios privados y manufacturas ${ }^{7}$ - que experimentaron muy lentos avances de productividad - . Solo en dos sectores relativamente pequeños, Agricultura y Pesca y Energía, fue significativo el avance de la productividad. Por lo tanto, el primer mensaje es que el lento crecimiento de la productividad agregada no tuvo como único origen el sector de la construcción - que efectivamente tuvo un crecimiento negativo - sino que se extendió a todos los sectores económicos con peso en la economía, las industrias manufactureras y todavía más en los sectores de servicios privados.

En segundo lugar, con la llegada de la crisis la productividad en España se recuperó de forma notable. Sin embargo - y como ya se mencionó anteriormente - esta recuperación no debe interpretarse como buenas noticias porque fue el resultado casi exclusivo de la intensísima destrucción de empleo en el sector de la construcción. El impacto fue tan notable que la tasa de variación de la productividad pasó del -1,4 por 100 anual en el periodo $1995-2007$, al +10,0 por 100 entre 2007 y 2011. El segundo sector que más empleo perdió, las Manufacturas, experimentó también una aceleración de su crecimiento, aunque de una magnitud muy inferior. En los servicios privados el avance de la productividad se mantuvo en los modestos límites de los años de expansión, y en la Agricultura y Pesca y Energía se desaceleró con la crisis.

\footnotetext{
${ }^{6}$ Para un detallado análisis microeconómico del comportamiento de la empresa española desde la perspectiva de la productividad, véase FERNÁNDEZ DE GUEVARA (2011).

$7^{*}$ En MAS y ROBLEDO (2010) se comprueba que este resultado es generalizable a la práctica totalidad de sectores manufactureros y de servicios privados, y no solo a sus correspondientes agregados.
} 


\section{GRÁFICO 9}

\section{TASA DE VARIACIÓN DE LA PRODUCTIVIDAD DEL TRABAJO. ECONOMÍA DE MERCADO, ESPAÑA, 1995-2011}

(En \%)

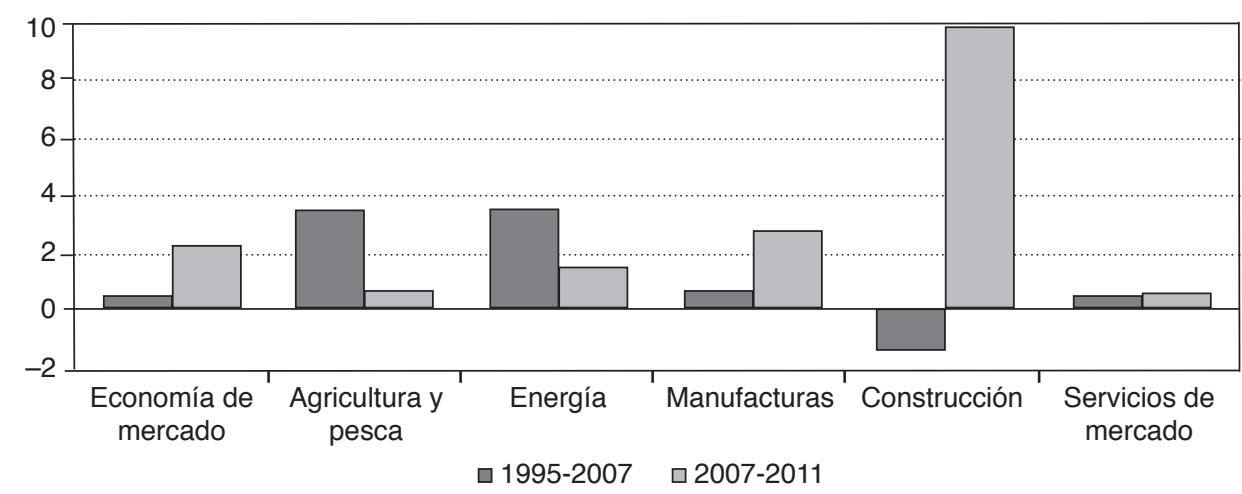

FUENTE: EU KLEMS (2011) e INE (2010 y 2011).

El pobre comportamiento del sector de la construcción no es, pues, el único responsable del lento avance de la productividad agregada en España. De hecho, este sector presenta crecimientos muy lentos, o incluso negativos, en la gran mayoría de los países. Por ejemplo, en Estados Unidos el crecimiento fue negativo entre los años 1995-2007, cuando en los restantes sectores el crecimiento fue muy importante. En el conjunto de la UE-25, y también en la UE-15 el crecimiento se aproximó a cero. Sin embargo en las economías de la UE-10, de fuerte crecimiento en estos años, su contribución fue positiva (Gráfico 10). Hay varias razones que explican el pobre comportamiento de la productividad en este sector siendo las más determinantes el tratarse de procesos de producción intensivos en mano de obra, y con dificultades en la introducción del progreso técnico, así como la relativamente baja estandarización de procesos y productos.

En los años de expansión el crecimiento de la productividad fue muy elevado en los Nuevos Estados Miembros (UE-10), Estados Unidos y Japón, más moderado en la UE-15 y francamente mediocre en España (Gráfico 3). Podemos preguntarnos qué sectores lideraron el crecimiento en los primeros, y se responsabilizaron del freno en España, es decir, cuál fue la contribución de cada sector al crecimiento agregado. Dicha contribución es el resultado de dos factores combinados: el crecimiento de la productividad en dicho sector, ponderado por su peso en el agregado. Es decir, un sector contribuye más al crecimiento agregado cuánto más rápido crece y cuánto más pesa en el conjunto de la economía.

El Gráfico 10 presenta las contribuciones sectoriales al crecimiento de la productividad en la economía de mercado $^{8}$. Los siguientes hechos resultan de interés. El

\footnotetext{
${ }^{8}$ Mientras el Gráfico 3 se refería al conjunto de la economía.
} 
primero, que en la UE-15, Estados Unidos y Japón, la contribución de las manufacturas fue de un orden de magnitud similar, mientras en la UE-10 fue prácticamente el doble al convertirse algunos de los países que la integran en auténticas fábricas de multinacionales. Lo que distingue, pues, a los tres primeros no es el mayor o menor dinamismo de las manufacturas. Lo que les distingue es la contribución de los servicios, muy superior en Estados Unidos que en la UE-15 o Japón. También fue la contribución de los servicios - especialmente de las ramas de comercio, transporte y comunicaciones - muy notable en los nuevos estados miembros que consiguieron beneficiarse de su incorporación a las economías capitalistas más desarrolladas. Por último, comprobamos que en España todos los sectores tuvieron contribuciones mediocres o negativas, como la ya mencionada de la construcción pero también la industria de Servicios Personales y Sociales.

\section{GRÁFICO 10 \\ CONTRIBUCIÓN SECTORIAL AL CRECIMIENTO DE LA PRODUCTIVIDAD POR HORA TRABAJADA. ECONOMÍA DE MERCADO, 1995-2007}

(En \%)

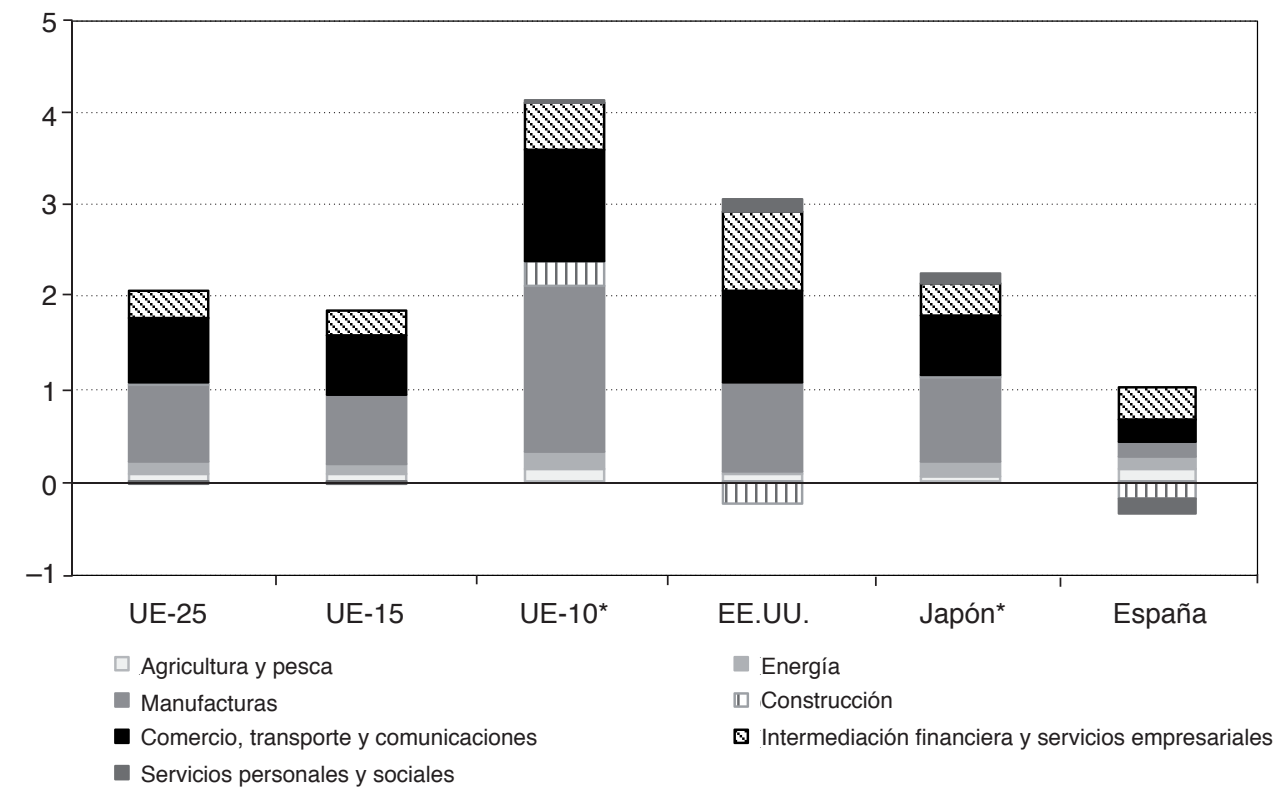

NOTA: * El período de referencia es 1995-2006.

FUENTE: EU KLEMS (2011) y elaboración propia. 


\section{Las fuentes del crecimiento y las nuevas tecnologías de la información y la comunicación (TIC)}

En este apartado nos preguntamos por qué unas economías han presentado crecimientos más elevados de la productividad del trabajo que otras, especialmente la española. Para responder a esta pregunta acudimos a la denominada contabilidad del crecimiento. Esta metodología descompone el incremento de la productividad del trabajo entre las contribuciones de tres fuentes: las mejoras en la cualificación de la fuerza de trabajo; el aumento en las dotaciones de capital por hora trabajada; y la productividad total de los factores (PTF), que se suele identificar con el progreso técnico no incorporado mediante las mejoras de la calidad del trabajo (capital humano) y del capital (como consecuencia de los cambios en su composición, en particular el aumento del capital en las TIC).

La información estadística disponible solo nos permite cubrir el periodo de expansión 1995-2007 para el conjunto de las economías que estamos considerando. Sin embargo, este hecho no debe considerarse limitativo ya que fueron precisamente en estos años cuando se pusieron los cimientos de una parte importante de los problemas con los que nos enfrentamos en la actualidad.

En el periodo 1995-2007 el crecimiento de la productividad del trabajo en España fue lento, casi la tercera parte que el de Estados Unidos (Gráfico 11). En este último país el importante aumento de la productividad del trabajo tuvo su origen en notables avances del progreso técnico (PTF) y una contribución del capital TIC que prácticamente triplicó a la del capital no TIC. En la UE- $15^{9}$ el crecimiento de la productividad fue más modesto que en Estados Unidos pero descansó en los mismos pilares: las mejoras en la PTF y la acumulación en capital TIC. En Japón, el gran motor del crecimiento de la productividad en estos años fue también la acumulación de capital TIC, seguida por el crecimiento de la PTF, y por las mejoras en la cualificación de la fuerza de trabajo y la acumulación de capital no TIC a partes iguales. En España, en cambio, el lento avance de la productividad tuvo un origen bien distinto: la PTF presentó un signo muy negativo y la contribución del capital no TIC superó a la del capital TIC. Por el contrario, la contribución de las mejoras en la cualificación de la fuerza de trabajo fue mucho mayor que en Estados Unidos o la UE-15. Puesto que nuestro nivel de cualificación de partida era inferior, las indudables mejoras derivadas del acceso a la educación superior tuvieron un recorrido mayor. Esta combinación de fuentes del crecimiento indica que en España la expansión se apoyó en incrementos sustanciales del capital por trabador y del capital humano, pero sin lograr generar valor con la suficiente intensidad como para conseguir ganancias de eficiencia. Es decir, nuestro crecimiento en estos años se fundamentó en el esfuerzo, en la acumulación de capital ligado a las actividades inmobiliarias, en gran parte financiada con el recurso al endeudamiento exterior que ahora nos está pasando una factura tan elevada.

${ }^{9}$ En realidad en el conjunto de diez países para los que disponemos de información, Alemania, Austria, Bélgica, Dinamarca, España, Finlandia, Francia, Italia, Países Bajos y Reino Unido, a los que la base de datos EU KLEMS se refiere como UE-15ex. 


\section{GRÁFICO 11 \\ CONTABILIDAD DEL CRECIMIENTO. PRODUCTIVIDAD POR HORA TRABAJADA. ECONOMÍA DE MERCADO, 1995-2007 \\ (En \%)}

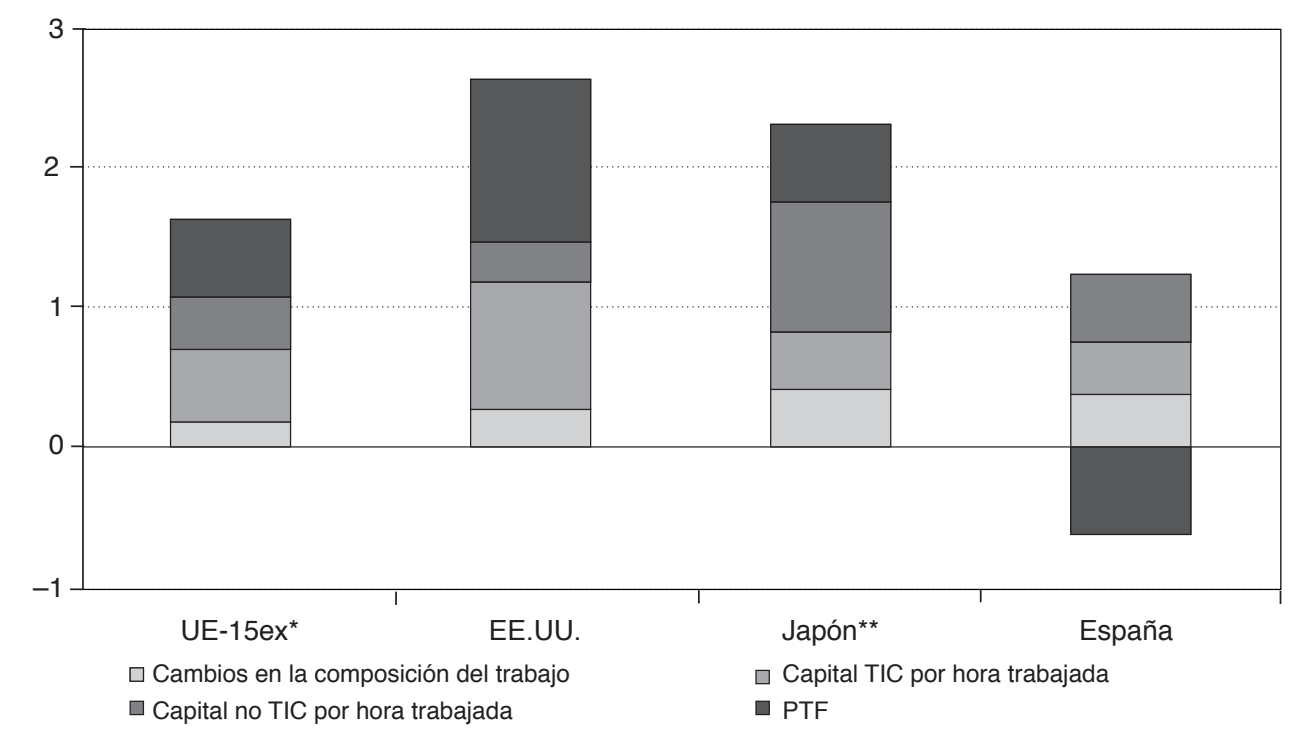

NOTA: * UE-15ex está formada por Alemania, Austria, Bélgica, Dinamarca, España, Finlandia, Francia, Italia, Países Bajos y Reino Unido. ** El período de referencia es 1995-2006.

FUENTE: EU KLEMS (2011) y elaboración propia.

Todos los países en los que la productividad creció a buen ritmo compartieron los mismos fundamentos: el avance de las mejoras de eficiencia medidas por la PTF, y la acumulación de capital TIC (Gráfico 12). Este es el caso de Finlandia, Estados Unidos, Austria, Países Bajos o Francia. En Irlanda, el país con mayor crecimiento de la productividad en estos años - que se encuentra en la actualidad con serios problemas - el origen fue distinto ya que se fundamentó, básicamente, en la acumulación de capital no TIC en primer lugar, y en las mejoras de eficiencia en segundo, mientras la contribución del capital TIC fue prácticamente testimonial. En el otro extremo del ranking aparecen España e Italia, ambas compartiendo dos características preocupantes: contribución negativa de la PTF e importante contribución del capital no TIC - como en Irlanda - materializado en fábricas, locales comerciales, o naves industriales. 


\section{GRÁFICO 12}

\section{CONTABILIDAD DEL CRECIMIENTO. PRODUCTIVIDAD POR HORA} TRABAJADA. ECONOMÍA DE MERCADO, 1995-2007

(En \%)

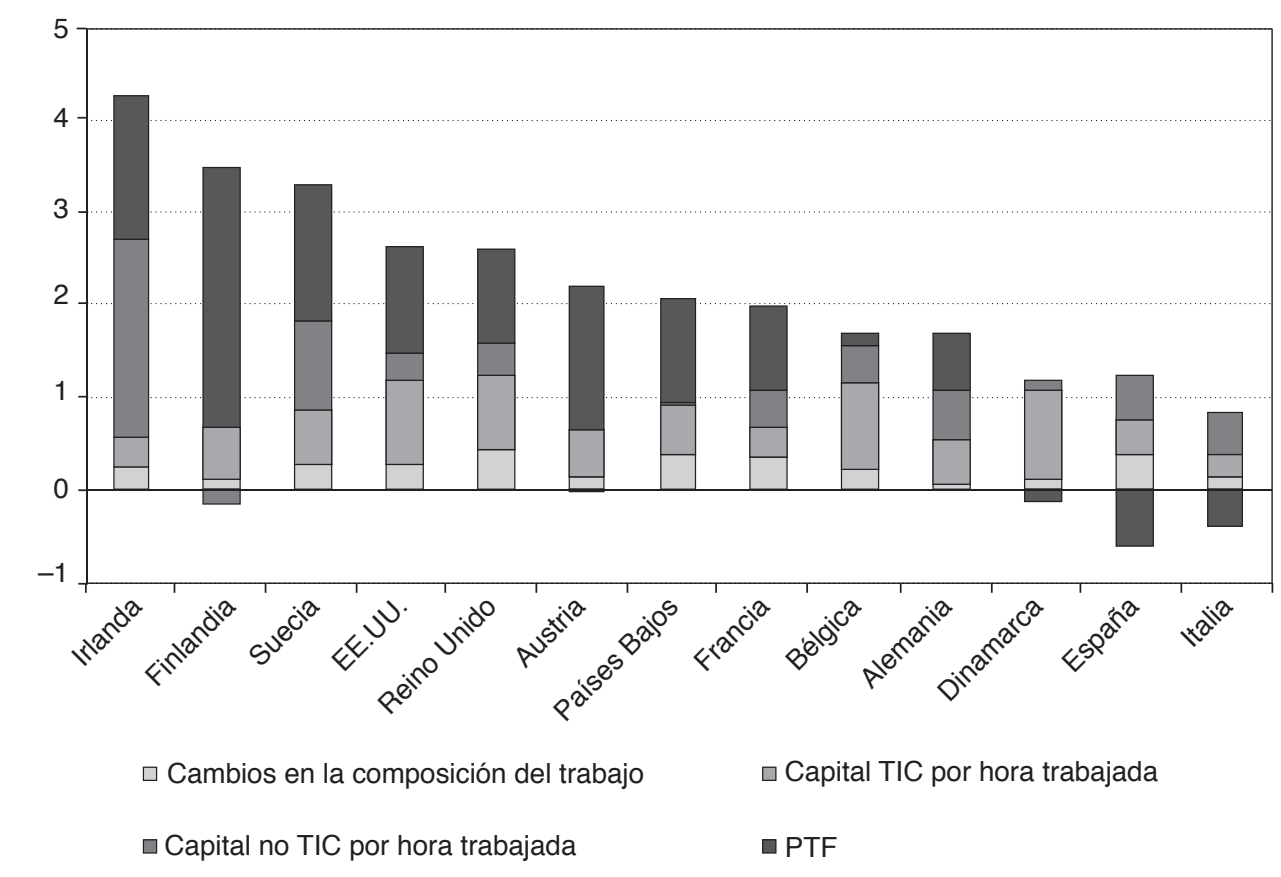

FUENTE: EU KLEMS (2011) y elaboración propia.

La importancia de las nuevas tecnologías en los patrones de crecimiento ha sido destacada por la literatura, especialmente desde mediados los años noventa del pasado siglo ${ }^{10}$. La influencia de las TIC se canaliza a través de dos vías. La primera - ya analizada haciendo uso de la Contabilidad del Crecimiento y reflejada en los gráfi$\cos 1.11$ y 1.12 - opera por la vía de la acumulación de capital en los tres activos ligados a las TIC, hardware, software, y equipos de comunicación. Es decir, por la vía de las TIC como factor de producción. El segundo canal de influencia opera por la vía de la especialización productiva. Aquí el argumento es que los países que han experimentado mayores crecimientos de la productividad son los que cuentan con un peso relativamente mayor de los sectores relacionados con las TIC, bien como productores o como usuarios intensivos de las nuevas tecnologías.

10 Véase, por ejemplo, MAS y QUESADA (2005) o MAS y SCHREYER (2006) y las referencias allí citadas. 
Los sectores productores de bienes TIC -Equipo eléctrico, electrónico y óptico y Telecomunicaciones - tienen un peso relativamente pequeño en las economías pero presentan crecimientos de la productividad muy elevados. De hecho, la ratio entre lo que contribuyen al crecimiento de la productividad agregada es aproximadamente tres veces superior al peso que tienen en el VAB. En España es el cuádruple y en los nuevos estados miembros es solo el doble (Gráfico 13). En los sectores que son usuarios intensivos de las TIC su contribución al crecimiento de la productividad es similar a su peso en el agregado - excepto en España que lo dobla- mientras que en los sectores con menor relación con las TIC la ratio es en general inferior, e incluso negativa como en nuestro país.

\section{GRÁFICO 13 \\ CONTRIBUCIÓN AL CRECIMIENTO DE LA PRODUCTIVIDAD POR HORA TRABAJADA/PARTICIPACIÓN EN EL VAB. ECONOMÍA DE MERCADO, 1995-2007}

(En \%)

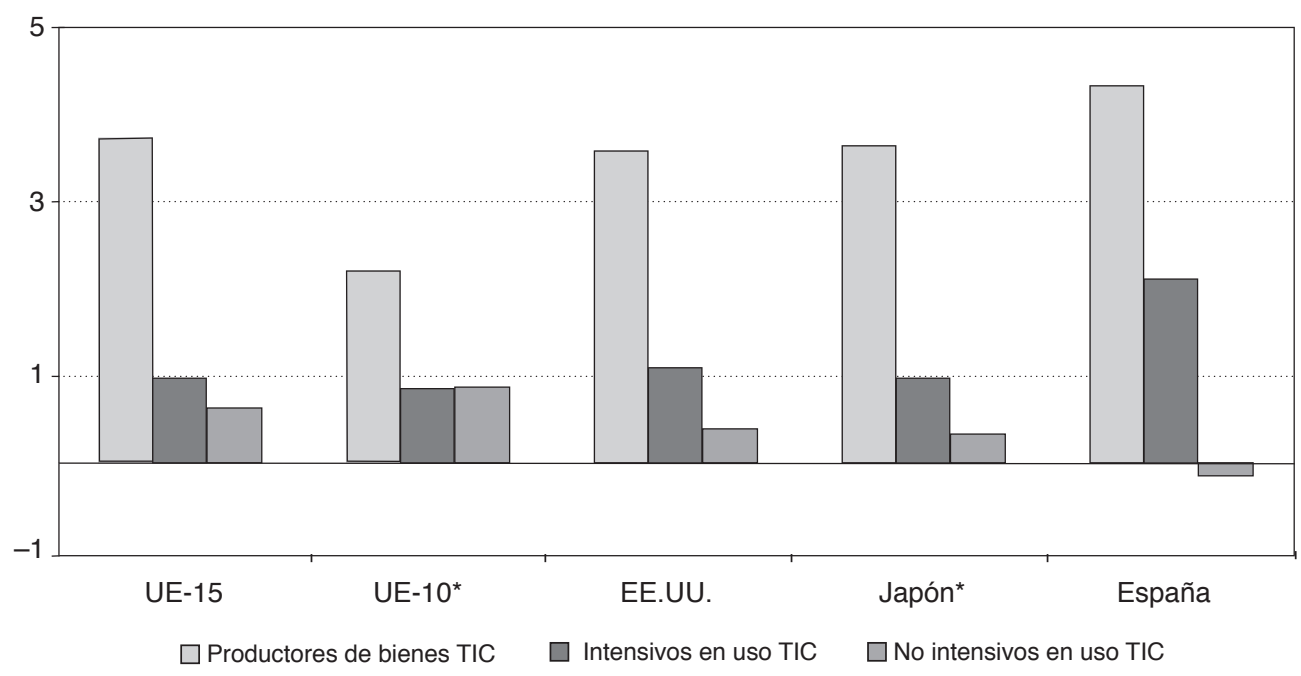

NOTA: * El período de referencia es 1995-2006.

FUENTE: EU KLEMS (2011) y elaboración propia.

Un hecho importante que conviene destacar es que son precisamente los sectores productores de nuevas tecnologías los que experimentan - con gran diferencia - los mayores ritmos de progreso técnico en todas las economías. España es la excepción porque incluso en este reducido grupo de industrias la PTF mostró una contribución negativa entre 1995 y 2007 (Gráfico 14). El segundo hecho digno de mención es que mientras en Estados Unidos las mejoras de eficiencia, el avance del progreso técnico, 
en los sectores productores se desbordaron a los sectores que utilizan las TIC de forma intensiva, ni en la UE-15 ni en Japón se produjo este fenómeno de desbordamiento, al menos no con la intensidad de Estados Unidos. En España, el crecimiento de la PTF fue negativo en las tres agregaciones sectoriales, incidiendo en la idea de que el problema de la productividad en nuestro país afecta a todos los sectores, tratándose por tanto de un problema general de funcionamiento de la economía más que de un problema de especialización productiva, aún admitiendo que el elevado peso del sector de la construcción ha sido un lastre que ahora nos está todavía pasando factura.

\section{GRÁFICO 14}

CONTABILIDAD DEL CRECIMIENTO. PRODUCTIVIDAD POR HORA TRABAJADA. ECONOMÍA DE MERCADO, 1995-2007

(En \%)

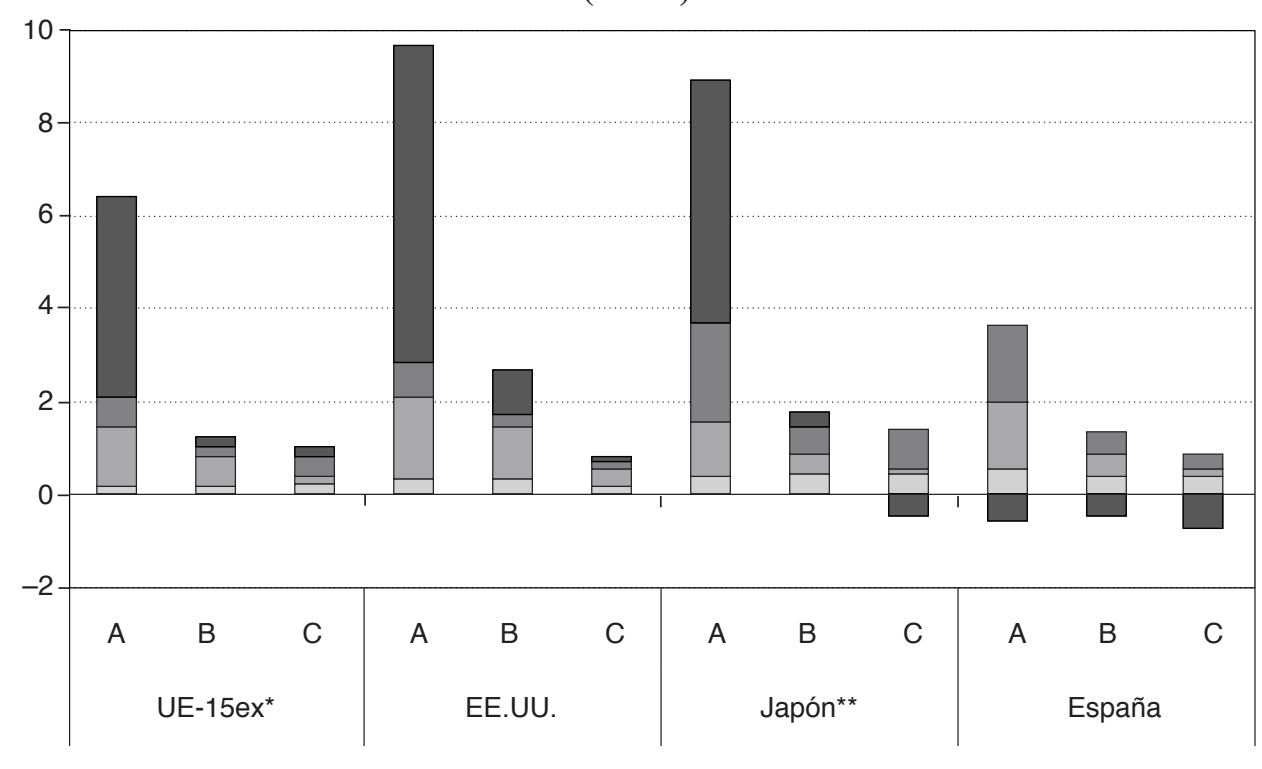

\footnotetext{
$\square$ Cambios en la composición del trabajo $\square$ Capital TIC por hora trabajada

$\square$ Capital no TIC por hora trabajada $\quad \square$ PTF
}

NOTAS: A: Productores de bienes TIC; B: Intensivos en uso TIC; C: No intensivos en uso TIC. * UE-15ex está formada por Alemania, Austria, Bélgica, Dinamarca, España, Finlandia, Francia, Italia, Países Bajos y Reino Unido. ** El período de referencia es 1995-2006.

FUENTE: EU KLEMS (2011) y elaboración propia. 


\section{Reflexiones finales}

Las dos ideas que han planeado de forma recurrente las líneas anteriores son, en primer lugar, los problemas de productividad del trabajo que presentó España en el periodo de crecimiento - que nos situó, junto con Italia, en los últimos lugares del ranking - y, en segundo lugar, la recuperación posterior en los años de crisis, que debe ser interpretada no como una buena noticia, sino como la resaca de los excesos cometidos en la etapa precedente.

El lento avance de la productividad en el periodo 1995-2007 fue un fenómeno compartido por prácticamente todos los sectores manufactureros y de servicios, $\mathrm{y}$ agravado por el negativo comportamiento del sector de la construcción. Por el contrario, en esos años la economía norteamericana experimentó un crecimiento sin precedentes que le permitió distanciarse de la más débil trayectoria de la UE, ganando en productividad y creando empleo. El hecho más notable de estos años es que el origen de la fortaleza en Estados Unidos se encontraba en el sector de los servicios privados, que experimentaron un fuerte despegue gracias a la extensión y aprovechamiento de las oportunidades que ofrecían las TIC.

La evidencia internacional indica que los países que mayores ganancias de productividad experimentaron en los años de expansión son los que mejor se están defendiendo en la actualidad. Estas ganancias se fundamentaron en dos motores: las mejoras en la eficiencia con la que se combinan los factores de producción, medida por la PTF, y la acumulación de capital TIC. Por el contrario, los países que más están sufriendo los embates de la crisis, como España e Italia, presentaron el comportamiento opuesto, fuerte acumulación de capital ligado a construcciones como fábricas, naves y locales, y contribuciones negativas de la Productividad Total de los Factores (PTF).

El hecho de que en España la práctica generalidad de los sectores presentaran lentos avances de productividad y que también experimentaran crecimientos negativos de la PTF con escasas excepciones, induce a pensar que en el origen no se encuentra - o no de forma exclusiva - la especialización productiva. Se trata, por el contrario, de un problema enraizado en el funcionamiento del sistema productivo que afecta a aspectos clave de la economía.

Fernández de Guevara y Mas (Pérez et al., 2012, capítulo 7) avanzan las siguientes razones en la explicación del negativo comportamiento de la PTF, y por lo tanto del lento crecimiento de la productividad del trabajo: 1. el continuo crecimiento de los costes laborales unitarios, fruto de un crecimiento de los salarios superiores al avance de la productividad; 2. La extensión de la contratación laboral - que impide el aprovechamiento del capital humano acumulado en el sistema educativo y desincentiva la formación por parte de las empresas - con consecuencias no solo sobre el sistema productivo sino también sobre la cohesión social al afectar más a jóvenes y mujeres; 3 . El reducido tamaño de las empresas españolas, con una presencia muy notable de las micro empresas y reducida de las grandes empresas, lo que impide aprovechar las economías de escala; 4 . El reducido peso de la inversión en nuevas 
tecnologías en relación con la acumulación en activos inmobiliarios. El objetivo no es tanto invertir más sino revertir el peso de los activos no TIC a favor de las TIC; 5. Las menores dotaciones en infraestructuras TIC en relación con los restantes países europeos pero, sobre todo, con el precio más elevado que se paga por ellas en España; 6. Poco aprovechamiento de las oportunidades que ofrecen las nuevas tecnologías, con una utilización de las mismas por parte de las empresas, el sistema educativo y las administraciones públicas, inferior a las de nuestros socios comerciales; 7. Pese a las indudables mejoras que hemos experimentado en las últimas décadas, las dotaciones de capital humano son todavía mejorables, como también lo es su aprovechamiento por parte de las empresas; 8 . Las regulaciones y barreras a la entrada en los sectores de comercio y servicios a empresas han tenido consecuencias negativas sobre la productividad de la economía española; y 9. Por último, y no menos importante, los bajos niveles de I+D de la economía española - especialmente de la realizada por las empresas privadas - ha contribuido de forma significativa a los pobres resultados presentados por la PTF. Este hecho es conocido desde hace tiempo pero no ha merecido la atención necesaria por nuestros gobernantes y va camino de empeorar peligrosamente en la actual etapa de recortes derivados de la requerida consolidación fiscal.

El listado anterior debería servirnos de guía, reconocer los errores pasados para evitar cometerlos de nuevo en el futuro. Desgraciadamente, algunas de las medidas que se están tomando en la actualidad no van en la dirección adecuada con el riesgo de que cuando salgamos del túnel en el que nos encontramos cometamos los mismos errores que nos llevaron a la situación actual de profunda recesión.

\section{Referencias bibliográficas}

[1] BCE (Banco Central Europeo) (2012): Monthly Bulletin. Septiembre de 2012. Frankfurt. Estadísticas disponibles en internet: http//sdw.ecb.europa.eu/reports.do?node= REPORTS.

[2] CUADRADO, J. R. y MAROTO, A. (2012): El problema de la productividad en España: Causas estructurales, cíclicas y sectoriales. Madrid: Fundación de las Cajas de Ahorros (FUNCAS).

[3] EU KLEMS (2011): EU KLEMS Growth and Productivity Accounts. Marzo de 2011. Base de datos disponible en la página web del proyecto www.euklems.net.

[4] EUROSTAT (2012): National Accounts. Luxemburgo. Banco de datos disponible en internet: http://appsso.eurostat.ec.europa.eu/nui/show.do?dataset=nama_aux_ulc\&lang=en.

[5] FERNÁNDEZ DE GUEVARA, J. (2011): La productividad sectorial en España: Una perspectiva micro. Bilbao: Fundación BBVA.

[6] HAGÉN, H. O. (2011): «Growth in the Nordic market economy», en Mas y Stehrer, Industrial Productivity in Europe, Growth and Crisis. Cheltenham (UK) y Northampton (MA, Estados Unidos): Edward Elgar.

[7] INE (Instituto Nacional de Estadística) (2010): Contabilidad Nacional de España. Base 2000. Serie 1995-2009. Madrid. 
[8] INE (2011): Contabilidad Nacional de España. Base 2008. Serie 2000-2010. Madrid.

[9] MAS, M. y QUESADA, J. (2005): Las nuevas tecnologías y el crecimiento económico en España. Bilbao: Fundación BBVA.

[10] MAS, M. y ROBLEDO, J. C. (2010): Productividad, Una Perspectiva Internacional y Sectorial. Bilbao: Fundación BBVA.

[11] MAS, M. y SCHREYER, P. (2006): Growth, capital and new technologies. Bilbao: Fundación BBVA.

[12] MAS, M. y STEHRER, R. (2012): Industrial Productivity in Europe, Growth and Crisis. Cheltenham (UK) y Northampton (MA, Estados Unidos): Edward Elgar.

[13] PÉREZ, F. (dir.); ALCALÁ, F.; FERNÁNDEZ DE GUEVARA, J.; MAS, M.; MAUDOS, J.; QUESADA, J.; REIG, E.; SERRANO, L.; BENAGES, E.; CHORÉN, P.; CUCARELLA, V.; ALBERT, C.; HERNÁNDEZ, L.; PÉREZ, J.; ROBLEDO, J. C.; SALAMANCA, J.; SOLAZ, M. y SOLER, A. (2012): Crecimiento y Competitividad. Motores y frenos de la economía española. Bilbao: Fundación BBVA.

[14] TCB (The Conference Board) (2012): Total Economy Database. Enero 2012. Nueva York. Disponible en internet: http://www.conference-board.org.

[15] TIMMER, M. P.; INKLAAR, R.; O’MAHONY, M. y VAN ARK, B. (2010): Economic Growth in Europe, A Comparative Industry Perspective. Cambridge (UK): Cambridge University Press. 